\title{
BMJ Amputations and socioeconomic position open among persons with diabetes mellitus, a population-based register study
}

\author{
Maarit Venermo, ${ }^{1}$ Kristiina Manderbacka, ${ }^{2}$ Tuija Ikonen, ${ }^{3}$ IImo Keskimäki, ${ }^{4,5}$ \\ Klas Winell, ${ }^{4}$ Reijo Sund ${ }^{2}$
}

To cite: Venermo $\mathrm{M}$, Manderbacka K, Ikonen T, et al. Amputations and socioeconomic position among persons with diabetes mellitus, a population-based register study. BMJ Open 2013;3:e002395. doi:10.1136/ bmjopen-2012-002395

- Prepublication history for this paper are available online. To view these files please visit the journal online (http://dx.doi.org/10.1136/ bmjopen-2012-002395).

Received 22 November 2012 Revised 18 February 2013 Accepted 22 February 2013

This final article is available for use under the terms of the Creative Commons Attribution Non-Commercial 2.0 Licence; see http://bmjopen.bmj.com

\section{ABSTRACT}

Objective: Low socioeconomic position is a known health risk. Our study aims to evaluate the association between socioeconomic position (SEP) and lower limb amputations among persons with diabetes mellitus.

Design: Population-based register study.

Setting: Finland, nationwide individual-level data. Participants: All persons in Finland with any record of diabetes in the national health and population registers from 1991 to 2007 (FinDM II database).

Methods: Three outcome indicators were measured: the incidence of first major amputation, the ratio of first minor/major amputations and the 2-year survival with preserved leg after the first minor amputation. SEP was measured using income fifths. The data were analysed using Poisson and Cox regression as well as age-standardised ratios.

Results: The risk ratio of the first major amputation in the lowest SEP group was 2.16 ( $95 \% \mathrm{Cl} 1.95$ to 2.38) times higher than the risk in the highest SEP group $(p<0.001)$. The incidence of first major amputation decreased by more than $50 \%$ in all SEP groups from 1993 to 2007 , but there was a stronger relative decrease in the highest compared with the lowest SEP group ( $p=0.0053$ ). Likewise, a clear gradient was detected in the ratio of first minor/major amputations: the higher the SEP group, the higher the ratio. After the first minor amputation, the 2-year and 10-year amputation-free survival rates were $55.8 \%$ and $9.3 \%$ in the lowest and $78.9 \%$ and $32.3 \%$ in the highest SEP group, respectively.

Conclusions: According to all indicators used, lower SEP was associated with worse outcomes in the population with diabetes. Greater attention should be paid to prevention of diabetes complications, adherence to treatment guidelines and access to the established pathways for early expert assessment when diabetic complications arise, with a special attention to patients from lower SEP groups.
For numbered affiliations see end of article.

\section{Correspondence to} Dr Maarit Venermo; maarit.venermo@hus.fi

\section{INTRODUCTION}

Poverty, poor education, low-occupational status as well as a poor-labour market situation have repeatedly been shown to constitute health risks. ${ }^{1}$ Several studies have shown

\section{ARTICLE SUMMARY}

Article focus

- Previous studies have shown a lowsocioeconomic position (SEP) to be associated with increased health risks. In recent years, declining amputation incidences among diabetic persons have been reported, but there is still a wide difference in amputation rates between countries and populations. Studies on the relationship of an individual's SEP and amputation risk among patients with diabetes are relatively scarce. Our study aims to evaluate the association between (SEP) and lower limb amputations among persons with diabetes mellitus.

Key messages

- Our results indicate that low SEP is associated with an increased risk of the first major amputation among persons with diabetes in Finland. The incidence of first major amputation decreased significantly by increasing income. Furthermore, the 2-year amputation-free survival rate after the first minor amputation was significantly higher in the highest SEP group when compared with the lower SEP groups. A similar association was also seen between income and the ratio of first minor/major amputations.

Strengths and limitations of this study

- We were able to use nationwide data collected from comprehensive administrative registers and link registers using identity codes. The data allowed us to examine the total population of Finnish residents treated for diabetes. We were also able to use individual register data on the SEP. On the downside, the national registries do not contain information on life style or health-related risk factors and some persons with diet-controlled diabetes who do not use any hypoglycaemic medication or have no hospital visits with diabetes diagnosis are missing from the data.

a low-socioeconomic position (SEP) to be associated with an increased risk of stroke at a younger age, ${ }^{2}{ }^{3}$ high mortality due to coronary heart disease ${ }^{4}$ and high case-death after the first cardiac event. ${ }^{5}$ 
A major amputation is a devastating complication of diabetes mellitus. In recent years, declining amputation incidences among diabetic persons have been reported, ${ }^{6}{ }^{7}$ but there is still a wide difference in amputation rates between countries and populations. ${ }^{8-11}$ Studies on the relationship of an individual's SEP and amputation risk are scarce, especially among diabetic patients. In Australia, Bergen et $a l^{12}$ have reported differences among persons with diabetes from deprived and non-deprived areas in diabetic ulcers, but not in amputation rates. In three other studies, the association between low SEP and high-amputation rate was reported in patients with critical limb ischaemia. ${ }^{13-15}$

The aim of the current study was to evaluate the relationship of lower limb amputation and SEP among diabetic individuals in Finland using three outcome indicators: the incidence of first major amputation, the ratio of first minor/major amputation and the 2-year survival rate with preserved leg after the first minor amputation.

\section{MATERIAL AND METHODS}

Our study utilised the FinDM II database, ${ }^{16}$ which comprises data on all diabetic individuals in Finland with any record of diabetes in the national healthcare and insurance registers for 1991-2007. The database was used to identify diabetic individuals and to follow-up on their amputations and deaths. Sociodemographic data were obtained from the longitudinal employment statistics database of Statistics Finland. The record linkages between and within the registers were carried out using the individual personal identity codes applied in all administrative registers in Finland.

Two criteria were applied to identify patients with a diabetes mellitus diagnosis: a person was on hypoglycaemic medication according to the national health insurance files or he/she had been hospitalised for diabetes according to the National Hospital Discharge Register. The use of hypoglycaemic medication is recorded in two National Health Insurance registers maintained by the Social Insurance Institution - the register on entitlements for special (elevated) health insurance reimbursement for hypoglycaemic medication (data from 1964 to 2007) and the register on reimbursed medication purchases (data 1994-2007) coded with the Anatomic Therapeutic Chemical classification system code A10. Hospital admissions in Finland are recorded in the National Hospital Discharge Register (data for 1969-2007) using the International Classification of Diseases (ICD) codes (www.who.int/classifications/icd/en). Diabetes is registered with the ICD-8-9 code 250 and ICD-10 codes E1014. The high health insurance reimbursement level for hypoglycaemic medication has resulted in a comprehensive coverage of individuals with diabetes in the medication registers. The Hospital Discharge Register is also comprehensive and covers both public and private hospitals. All hospitals in Finland have a legal obligation to report all hospital discharges. Up until 2008, mortality among individuals with diabetes was monitored in the Causes of Death Register of Statistics Finland.

In the present study, those who were not permanent residents of Finland or had gestational diabetes only were excluded from the analyses. A comparison against a local diabetes register of the Helsinki metropolitan area has demonstrated good coverage of diabetic patients in the nationwide register. ${ }^{17} \mathrm{~A}$ more comprehensive description of the study population is available elsewhere. $^{16}$

In 1993, the number of persons with diabetes was 130244 (26049/SEP group), and it increased to 274388 (54 878/SEP group) by 2007.

\section{Amputations}

After identifying all persons treated for diabetes in the country, the data were cross-linked with the National Hospital Discharge Register using the personal identity codes to identify which patients had sustained a lower extremity amputation (LEA) (NOMESCO procedure codes NFQ20, NGQ10, NGQ20, NHQ10, NHQ20, NHQ30 and NHQ40 or Finnish Hospital League procedure codes 9571, 9572, 9573, 9574 and 9575) from 1987 to 2007. All amputations above the ankle were considered major and those below the ankle minor (codes NHQ20, NHQ30, NHQ40, 9571 and 9572). We excluded amputations due to neoplasm or trauma (with the exception of those with the ICD-10 codes S90-91, T80-81 and T87.3-T87.6).

\section{Socioeconomic position}

We used income as an indicator of SEP. The net household income was obtained from tax records included in the annual employment statistics databases compiled from several administrative registers by Statistics Finland. The annual incomes of persons with diabetes were classified into quintiles adjusted for family size using the OECD equivalence scale. ${ }^{18}$ The analyses were also performed using register data concerning educational attainment, that is, basic (up to 9 years), intermediate (10-12 years) and higher (13 or more years) education as an indicator of SEP.

\section{Statistical methods}

The first major amputations (preceding a 10-year amputation-free period) among persons with diabetes were identified and stratified according to age group, sex, type of diabetes, duration of diabetes and year of amputation. The adjusted impact of these variables on the incidence of first major amputation was analysed using the Poisson regression model.

The minor/major amputation ratios were calculated by dividing the number of all first amputations classified as minor by those classified as major. Ratios were calculated for each SEP group using a 3-year time window (moving) over the follow-up period.

Survival analyses were used to study the time elapsed from the first minor amputation to death or major 
amputation. Unadjusted survival with preserved leg was studied using the Kaplan-Meier product-limit estimator, and the adjusted effect of SEP was analysed using the Cox proportional hazards model. The result was considered censored at the final day of 2008 if no event of interest had occurred before that.

All statistical analyses were performed using the R software package with the library Muste (www.survo.fi/ muste).

The study protocol was approved by the Institutional Ethics Committee of National Institute for Health and Welfare $(\$ 367 / 2011)$, and the permissions to use register data were applied from the National Institute for Health and Welfare, Statistics Finland and Social Insurance Institution. Informed consents were not required since the data were anonymous register data and the people were not contacted.

\section{RESULTS}

First major amputation

In 1993, the crude incidence of first major amputations per 100000 person-years among persons with diabetes (pyrs) was 420 (95\% CI 386 to 456). The incidence decreased steadily during the study period, being 154 (95\% CI 139 to 169) in 2007. In 1993, the crude incidence was roughly 600 in the lowest SEP group and 200 in the highest. The incidence decreased significantly in all SEP groups during the study period, being 260 in the lowest and 60 in the highest SEP group in 2007 (figure 1). In the Poisson regression model adjusted for age, sex, type of diabetes, year and diabetes duration, higher income was associated with a decreased risk of first major amputation $(\mathrm{p}<0.001 ;$ table 1$)$. In the highest income group, the relative risk was 0.46 in comparison to the lowest income group. In the highest educational group, the relative risk

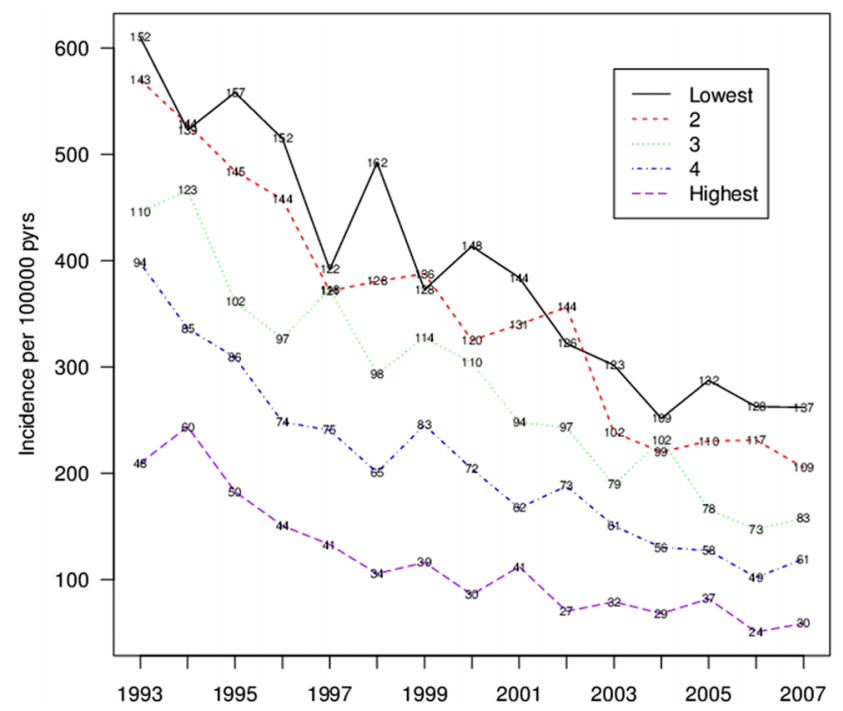

Figure 1 The crude incidence of the first major amputation among diabetic persons by income quintile in Finland from 1993 to 2007.
Table 1 Risk factors for first major amputation* among persons with diabetes in Finland in 1991-2007 (Poisson regression model)

\begin{tabular}{|c|c|c|c|}
\hline Risk factor & $\begin{array}{l}\text { Rate } \\
\text { ratio }\end{array}$ & $95 \% \mathrm{Cl}$ & $\begin{array}{l}\text { p Value } \\
\text { (Walds test) }\end{array}$ \\
\hline \multicolumn{4}{|l|}{ SEP } \\
\hline 1 (Lowest) & 1.00 & (ref) & \\
\hline 2 & 0.89 & 0.83 to 0.95 & $<0.001$ \\
\hline 3 & 0.81 & 0.75 to 0.86 & $<0.001$ \\
\hline 4 & 0.70 & 0.65 to 0.76 & $<0.001$ \\
\hline 5 (Highest) & 0.46 & 0.42 to 0.51 & $<0.001$ \\
\hline Age (years) & $30-39$ & 1.00 & (ref) \\
\hline $50-64$ & 3.07 & 2.67 to 3.52 & $<0.001$ \\
\hline $65-74$ & 6.28 & 5.49 to 7.18 & $<0.001$ \\
\hline $75-84$ & 10.6 & 9.28 to 12.2 & $<0.001$ \\
\hline $85+$ & 15.1 & 13.1 to 17.5 & $<0.001$ \\
\hline \multicolumn{4}{|l|}{ Gender } \\
\hline Men & 1.00 & (ref) & \\
\hline Women & 0.62 & 0.59 to 0.65 & $<0.001$ \\
\hline \multicolumn{4}{|l|}{ Diabetes type } \\
\hline ITDM & 1.00 & (ref) & \\
\hline NITDM & 0.57 & 0.54 to 0.61 & $<0.001$ \\
\hline \multicolumn{4}{|l|}{$\begin{array}{l}\text { Diabetes } \\
\text { duration (years) }\end{array}$} \\
\hline $0-9$ & 1.00 & (ref) & \\
\hline $10-19$ & 2.50 & 2.36 to 2.64 & $<0.001$ \\
\hline $20+$ & 3.30 & 3.09 to 3.52 & $<0.001$ \\
\hline Amputation year & 0.93 & 0.92 to 0.93 & $<0.001$ \\
\hline
\end{tabular}

was 0.54 (95\% CI 0.49 to $0.60, \mathrm{p}<0.001$ ) compared with the group with basic education only.

\section{Ratio of first minor/major amputations}

During the study period, the ratio of first minor/major amputations increased steadily. A gradient was detected by income: the higher the income group, the higher the ratio. This gradient persisted throughout the study period. Furthermore, the differences were remarkably large between the highest income group and other groups (figure 2). A similar pattern was detected for education: the group with basic education only was clearly different from the groups with intermediate and highest (data not shown).

\section{Two-year survival with preserved leg after the first minor amputation}

The 2-year amputation-free survival after the first minor amputation was $55.8 \%$ in the lowest SEP group and $78.9 \%$ in the highest SEP group. The 10-year amputation-free survival percentages were 9.3 and 32.3 , respectively (figure 3 ). In the Cox regression model with 2-year follow-up adjusted for age, sex, diabetes duration, year and diabetes type, higher income was associated with lower risk of death and/or major amputation after the first minor amputation. While the differences 


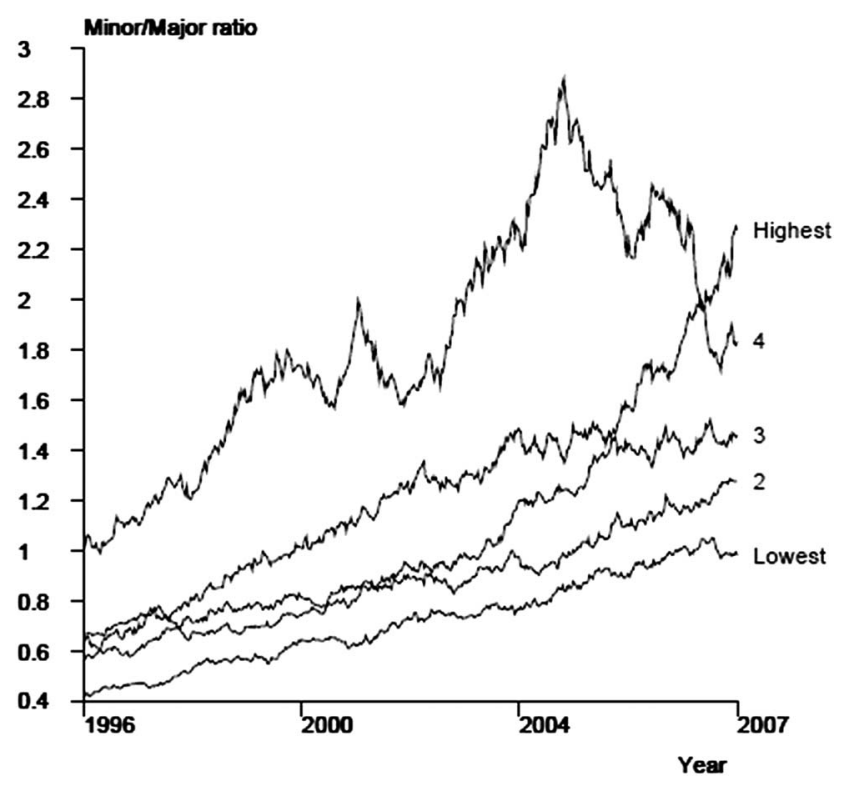

Figure 2 The ratio of minor and major amputations among diabetic persons by income group in Finland in 1993-2007 (calculated by sliding a 3-year-wide observation window over the follow-up period).

between the three lowest income groups were not statistically significant, the amputation-free survival was significantly higher in the two highest income groups when compared with the lowest income group (table 2). For education, the differences were statistically significant: in the group with the highest education, the relative risk was $0.71(95 \%$ CI 0.62 to $0.80, \mathrm{p}<0.001)$ compared with the group with only basic education.

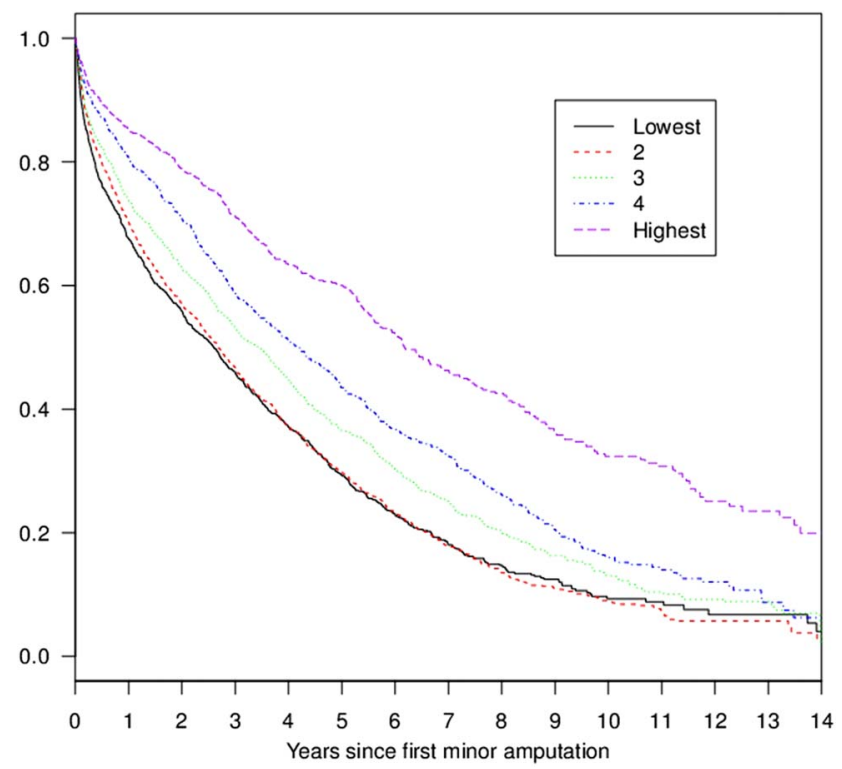

Figure 3 Unadjusted amputation-free survival with the leg intact/preserved after first minor amputation among diabetic persons by income group in Finland from 1993 to 2007 (Kaplan-Meier product-limit estimator).
Table 2 Risk factors for major amputation and/or death during 2 years after first minor amputation among persons with diabetes in Finland in 1991-2007 (Cox regression model)

\begin{tabular}{|c|c|c|c|}
\hline Risk factor & HR & $95 \% \mathrm{Cl}$ & $\begin{array}{l}\text { p Value } \\
\text { (Walds test) }\end{array}$ \\
\hline \multicolumn{4}{|l|}{$\overline{\text { SEP }}$} \\
\hline 1 (Lowest) & 1.00 & (ref) & \\
\hline 2 & 0.98 & 0.90 to 1.07 & 0.6989 \\
\hline 3 & 0.95 & 0.86 to 1.05 & 0.3001 \\
\hline 4 & 0.89 & 0.80 to 1.00 & 0.0405 \\
\hline 5 (Highest) & 0.68 & 0.60 to 0.77 & $<0.001$ \\
\hline Risk/10 years & 1.64 & 1.58 to 1.70 & $<0.001$ \\
\hline \multicolumn{4}{|l|}{ Gender } \\
\hline Men & 1.00 & (ref) & \\
\hline Women & 0.93 & 0.86 to 0.99 & 0.0317 \\
\hline \multicolumn{4}{|l|}{ Diabetes type } \\
\hline $\begin{array}{l}\text { ITDM (-40 at } \\
\text { incidence date) }\end{array}$ & 1.00 & (ref) & \\
\hline $\begin{array}{l}\text { ITDM (40+ at } \\
\text { incidence date) }\end{array}$ & 0.99 & 0.84 to 1.16 & 0.8550 \\
\hline NITDM & 1.09 & 0.93 to 1.27 & 0.2543 \\
\hline \multicolumn{4}{|l|}{ Diabetes duration } \\
\hline Risk/10 years & 1.12 & 1.08 to 1.17 & $<0.001$ \\
\hline Amputation year & 1.00 & 1.00 to 1.01 & 0.3275 \\
\hline
\end{tabular}

ITDM, insulin-treated diabetes mellitus; NITDM, non-insulin-treated diabetes mellitus.

\section{DISCUSSION}

\section{Principal findings}

Our results indicate that low SEP is associated with an increased risk of the first major amputation among persons with diabetes in Finland. The incidence of first major amputation decreased significantly by increasing income. Furthermore, the 2-year amputation-free survival rate after the first minor amputation was significantly higher in the highest SEP group when compared with the lower SEP groups. A similar association was also seen between income and the ratio of first minor/major amputations. Thus, our results are in line with other studies suggesting an increased amputation risk in patients with critical limb ischaemia in the low-SEP population. ${ }^{12-15}$

\section{Strengths and weaknesses of the study}

The main weakness of our study is that with our registerbased data, we were not able to control for some important clinical or life-style or health-related factors, such as body mass index or smoking, that are likely to affect the outcome. However, the major strength is that we were able to use nationwide data collected from comprehensive administrative registers. It is known, for instance, that the validity of the Finnish Hospital Discharge Register is high and that the Finnish Causes of Death statistics are valid and reliable by international standards. $^{19} 20$ The data allowed us to examine the total population of Finnish residents treated for diabetes 
although our data are likely to miss some persons with diet-controlled diabetes mellitus who are not using any hypoglycaemic medication or do not have any hospital visits with diabetes diagnosis. We were also able to use individual register data on the SEP. The socioeconomic data used in the study were based on longitudinal data files containing information from tax registers and from several registers maintained by Statistics Finland. Data on the vascular surgical procedures on the lower extremity did not include all the endovascular procedures in the used registers, which made it impossible to examine how much of the differences in outcomes could have been explained by limited access to vascular surgery in the lower SEP groups.

\section{Strengths and weaknesses in relation to other studies, discussing particularly any differences in results}

The crude incidence of the first major lower limb amputations in Finland seems to be somewhat higher than in some other countries. ${ }^{7}{ }^{10}$ For example, the crude incidences were 1.54 (per 1000 of diabetes population) and 7.98 (per 100000 of general population) in Finland in 2007 , while the corresponding incidences were reported to be 1.26 and 4.43 in Scotland. ${ }^{7}$ Such comparisons of crude incidences are not without problems. Population structures may be different, and the use of denominator including all age groups may be misleading as most amputations are performed for older persons. Furthermore, calculation of crude incidences and standardised incidences as reported in our earlier study ${ }^{6}$ provides different figures from the same data. Therefore, when incidence figures are concerned, the rates are comparable only within one study, while the relative comparisons are much more suitable for benchmarking purposes. Differences in incidences between populations could be related to prevention measures, access to care, treatment decisions and options available for reconstructive vascular surgery. This interpretation is supported by the reported regional differences of amputation rates observed in some countries. ${ }^{10} 11$

In the USA, several studies have shown that African-American patients undergo a major lower extremity amputation two to three times more frequently than Caucasian patients. ${ }^{21}{ }^{22}$ An explanation suggested by Feinglass $e t a l^{22}$ is SEP differences between ethnic groups. A cross-sectional study including $20 \%$ of all non-federal hospital discharges in the USA ${ }^{13}$ found that a primary amputation was performed with a higher frequency on patients with lower extremity ischaemia who were non-white, had a low income and were not covered by private insurance. A delayed diagnosis of peripheral arterial disease (PAD), a lack of access to adequate primary care or vascular surgery, or both, as well as cultural distrust may explain these findings. ${ }^{13}$ Some studies from the USA have also found large regional differences in LEAs among Medicare recipients with and without diabetes ${ }^{11} 23$ even after controlling for patient characteristics including sex, age and ethnic background. The authors suggest that these variations could be related to treatment practices, access to and use of preventive care among patients, and health-based education of the patients and their treatment preferences.

\section{Meaning of the study: possible mechanisms and} implications for clinicians or policymakers

A major amputation is an end stage of a progressive disease, while almost all patients with diabetes who undergo an amputation have developed neuropathy and $\mathrm{PAD}$, and many of them also suffer from infections and renal insufficiency. ${ }^{24}$ Comprehensive diabetes care, however, probably slows down the progress of the disease and reduces the risk of major amputations. Our results suggest that the long-term treatment of diabetes may have been less successful among lower SEP groups over the years. Low SEP has been reported to be a risk factor for poor glycaemic control in young persons with type 1 diabetes. ${ }^{25} 26$ The prevalence of risk factors can differ between different socioeconomic groups. In Finland, for example, smoking is more common among lower SEP groups. ${ }^{27}{ }^{28}$ Smoking is a very strong risk factor of PAD. ${ }^{29}$ During the period 2000-2004, about $38 \%$ of adult Finnish men with lowest education were smokers compared with $17 \%$ with the highest education smoked in Finland. ${ }^{28}$ The corresponding figures for women were $28 \%$ and $13 \%$. Smoking persons with diabetes have more proximal amputations. ${ }^{30}$ Part of the explanation to differences in outcomes is likely to be worse hyperglycaemia and higher prevalence of smoking in the lower SEP groups.

In Finland, like in many industrialised countries, equal access to healthcare according to need has been an important goal for health policy for decades. All residents in Finland have access to primary and secondary healthcare, independent of their SEP, when attention to a health problem is needed. ${ }^{31}$ The municipalities have the main responsibility of provision of healthcare for the residents. Ambulatory and hospital services are primarily provided by the public sector and are mainly financed through taxation and user fees are low, but there have been problems in long waiting times. For employees, occupational healthcare provides easy and free of charge access to ambulatory care. In urban areas, private ambulatory services are available, but for patients deductibles are high (over $60 \%$ on average). However, care for patients with diabetic complications, as well as peripheral vascular surgery and limb amputations, is almost exclusively provided by the public healthcare system. In addition to sluggish access to public ambulatory services, the Finnish healthcare system has been slow to adopt active methods of improving treatment for patients with chronic conditions. ${ }^{32}$ Disease registers, call-recall systems and outreach services, which are uncommon in Finland, could help to improve continuity of personal care among disadvantaged patients with complicated diabetes. Timely and adequate healthcare could 
ameliorate the potential long-term adverse consequences of SEP differences, as a recent study in Finland suggested while showing that SEP is not associated with the effectiveness of lifestyle interventions in persons with a high risk for diabetes. ${ }^{33}$

The association between SEP and the ratio of first minor/major amputations was clear in our study. This indicates that major amputations are performed more often as the first amputation in lower SEP groups, whereas the number of minor amputations is relatively higher in higher SEP groups. The factors that influence the level of amputation are the size and location of the lesion in the foot, the patient's ambulatory status and the blood supply to the foot. ${ }^{34}$ The goal of vascular surgery is to avoid major amputations and to improve circulation to enable wound healing. Indeed, an inverse correlation between the rate of distal bypass operations and amputation incidence has been established. ${ }^{35} 36$ However, if the tissue lesion in a foot is extremely large or there is a widespread infection, major amputation may be the first choice. The results by Henry et $a l^{14}$ suggest an inverse association between SEP and lower extremity revascularisation rates in patients with critical limb ischaemia. Unfortunately, our register did not include revascularisation data.

The 2-year amputation-free survival rate after the first minor amputation was significantly lower in the lower SEP groups as compared with the higher SEP groups. This result seems to suggest inequities in the care of these patients even after their limb-threatening situation has been identified by healthcare professionals. Since all of these patients have undergone their first minor amputation, their treatment schema should have been similar after the beginning of the follow-up. All of these patients have been in contact with healthcare due to the amputation and should have undergone an assessment of blood supply to the foot. Furthermore, they should all have had equal follow-up after the minor amputation. Yet, patients with low income are more likely to die or undergo a subsequent major amputation.

In the current study, the classification of SEP was based on family income. We also carried out our analyses using education as an indicator of SEP, and the main results remained the same. Persons with a higher education had a significantly lower incidence of first major amputations, a higher minor/major amputation ratio and a better 2-year amputation-free survival rate than those with basic education only.

\section{CONCLUSION}

Our results suggest that SEP is associated with a risk of amputation in patients with diabetes. Those in a lower SEP are more likely to sustain amputations, and their amputations are more likely to be major amputations, leading to more severe disability. Low SEP also increases the risk of death and/or major amputation after the first minor amputation. More attention needs to be paid to addressing the risk factors for diabetic complications and life style, especially among patients from lower socioeconomic groups, during all contacts with healthcare from the early stages of diabetes to vascular treatment and rehabilitation.

Author affiliations

${ }^{1}$ Department of Vascular Surgery, Helsinki University Central Hospital, Helsinki, Finland

${ }^{2}$ Service System Research Unit, National Institute for Health and Welfare, Helsinki, Finland

${ }^{3}$ Technologies and Practices Assessment Unit, National Institute for Health and Welfare, Helsinki, Finland

${ }^{4}$ Division of Health and Social Services, National Institute for Health and Welfare, Helsinki, Finland

${ }^{5}$ School of Health Sciences, University of Tampere, Tampere, Finland

Contributors MV, KM, IK, KW, TI and RS conceived the idea of the study. $\mathrm{RS}$ and IK were responsible for the design of the study. RS, KM and MV were responsible for undertaking the data analysis and produced the tables and graphs. IK and KW provided input into the data analysis. The initial draft of the manuscript was prepared by MV and KM and then circulated repeatedly among all authors for critical revision. TI made the major revisions. RS was responsible for the acquisition of the data and MV, KM, IK, TI and KW contributed to the interpretation of the results. All authors read and approved the final manuscript.

Funding The study was financially supported by the Social Insurance Institution, but the SII had no involvement in its design, data collection, findings or decision to publish.

Competing interests All authors included on the paper fulfil the criteria or authorship. An authorship statement form is attached to the submission.

Provenance and peer review Not commissioned; externally peer reviewed.

Data sharing statement No additional data are available.

\section{REFERENCES}

1. Commission on Social Determinants of Health. Closing the gap in a generation. Health equity through action on the social determinants of health. Geneva: World Health Organisation, 2008.

2. Avendano M, Glymour MM. Stroke disparities in older Americans: is wealth a more powerful indicator of risk than income and education? Stroke 2008;39:1533-40.

3. Kerr GD, Higgins $P$, Walters $M$, et al. Socioeconomic status and transient ischaemic attack/stroke: a prospective observational study. Cerebrovasc Dis 2011;31:130-7.

4. Chang WC, Kaul P, Westerhout $\mathrm{CM}$, et al. Effects of socioeconomic status on mortality after acute myocardial infarction. Am J Med 2007;120:33-9.

5. Manderbacka K, Hetemaa T, Keskimäki I, et al. Are there socioeconomic differences in Ml event rates and fatality among patients with angina pectoris? J Epidemiol Community Health 2006;60:442-7.

6. Ikonen TS, Sund R, Venermo M, et al. Fewer major amputations among individuals with diabetes in Finland in 1997-2007: a population-based study. Diabetes Care 2010;33:2598-603.

7. Kennon B, Leese GP, Cochrane L, et al. Reduced incidence of lower-extremity amputations in people with diabetes in Scotland: a nationwide study. Diabetes Care 2012;35:2588-90.

8. Jeffcoate WJ. The incidence of amputation in diabetes. Acta Chir Belg 2005;105:140-4.

9. Shaw J. Diabetes: regional variation in lower limb amputation incidence. Nat Rev Endocrinol 2012;8:386-8.

10. Holman N, Young RJ, Jeffcoate WJ. Variation in the recorded incidence of amputation of the lower limb in England. Diabetologia 2012;55:1919-25.

11. Margolis DJ, Hoffstad O, Nafash J, et al. Location, location, location: geographic clustering of lower-extremity amputation among Medicare beneficiaries with diabetes. Diabetes Care 2011;34:2363-7.

12. Bergen SM, Brand CA, Colman PG, et al. The impact of socioeconomic disadvantage on hospital separations for diabetes related foot disease in Victoria, Australia. J Foot Ankle Dis 2011;4:17. 
13. Eslami MH, Zayaruzny M, Fitzgerald GA. The adverse effects of race, insurance status, and low income on the rate of amputation in patients presenting with lower extremity ischemia. $J$ Vasc Surg 2007:45:55-9.

14. Henry AJ, Hevelone ND, Belkin M, et al. Socioeconomic and hospital-related predictors of amputation for critical limb ischemia. J Vasc Surg 2011;53:330-9.

15. Ferguson HJM, Nightingale $P$, Pathac $R$, et al. The influence of socioeconomic deprivation on rates of major lower limb amputation secondary to peripheral arterial disease. Eur J Vasc Endovasc Surg 2010;40:76-80.

16. Sund R, Koski S, Fin DM II. On the register-based measurement of the prevalence and incidence of diabetes and its long-term complications. Tampere: Finnish Diabetes Association; 2009. A technical report.

17. Sund R, Harno K, Ranta S, et al. Evaluation of case inclusion in two population-based diabetes registers. Finnish $\mathrm{J}$ eHealth eWelfare 2010;2:136-46.

18. What are equivalence scales? http://www.oecd.org/LongAbstract/ 0,3425,en_2649 33933 35411112_119669_1_1_1,00.html (accessed 31 Mar 2013).

19. Sund R. Quality of the Finnish hospital discharge register: a systematic review. Scan J Public Health 2012;40:505-15.

20. Lahti R. From findings to statistics: an assessment of Finnish medical cause-of-death information in relation to underlying-cause coding. Helsinki: Department of Forensic Medicine, University of Helsinki, 2005.

21. Rucker-Whitaker C, Feinglass J, Pearce WH. Explaining racial variation in lower extremity amputation: a 5-year retrospective claims data and medical record review at an urban teaching hospital. Arch Surg 2003;138:1347-51.

22. Feinglass $\mathrm{J}$, Rucker-Whitaker $\mathrm{C}$, Lindquist $\mathrm{L}$, et al. Racial differences in primary and repeat lower extremity amputation: results from a multihospital study. J Vasc Surg 2005;41(5):823-9.

23. Wrobel JS, Mayfield JA, Reiber GE. Geographic variation of lower-extremity major amputation in individuals with and without diabetes in the Medicare population. Diabetes Care 2001; 24:860-4.

24. Oyibo SO, Jude EB, Voyatzoglou D, et al. Clinical characteristics of patients with diabetic foot problems: changing patterns of foot ulcer presentation. Pract Diabetes Int 2002;19:10-12.

25. Gallegos-Macias AR, Macias SR, Kaufman E, et al. Relationship between glycemic control, ethnicity and socioeconomic status in
Hispanic and white non-Hispanic youths with type 1 diabetes mellitus. Pediatr Diabetes 2003;4:19-23.

26. Galler A, Lindau M, Ernert A, et al. Associations between media consumption habits, physical activity, socioeconomic status, and glycemic control in children, adolescents, and young adults with type 1 diabetes. Diabetes Care 2011;34:2356-9.

27. Helakorpi S, Laitalainen E, Uutela A. Suomalaisen aikuisväestön terveyskäyttäytyminen ja terveys, kevät 2009 (in finnish: health behaviour and health among the Finnish adult population, Spring 2009). Helsinki: Terveyden ja hyvinvoinnin laitos (THL); 2010 Raportti/Terveyden ja hyvinvoinnin laitos $(\mathrm{THL})=$ Report/National Institute for Health and Welfare..

28. Aromaa A, Koskinen S. Health and functional capacity in Finland. Baseline results of the Health 2000 Health Examination Survey. Helsinki: Publications of the National Public Health Institute B12/ 2004, 2004

29. Joosten MM, Pai JK, Bertoia ML, et al. Associations between conventional cardiovascular risk factors and risk of peripheral artery disease in men. JAMA 2012;308:1660-7.

30. Anderson JJ, Boone J, Hansen M, et al. A comparison of diabetic smokers and non-smokers who undergo lower extremity amputation: a retrospective review of 112 patients. Diabet Foot Ankle 2012;3. doi:10.3402/dfa.v3i0.19178

31. Vuorenkoski L, Mladovsky P, Mossialos E. Finland: health system review. Health systems in transition. UK: WHO, 2008.

32. Mäntyselkä $P$, Halonen $P$, Vehviläinen $A$, et al. Access to and continuity of primary medical care of different providers as perceived by the Finnish population. Scand J Prim Health Care 2007;25:27-32.

33. Rautio N, Jokelainen $\mathrm{J}$, Oksa $\mathrm{H}$, et al. Socioeconomic position and effectiveness of lifestyle intervention in prevention of type 2 diabetes: one-year follow-up of the FIN-D2D project. Scand J Public Health 2011;39:561-70.

34. Söderström M, Aho PS, Lepäntalo M, et al. The influence of the characteristics of ischemic tissue lesions on ulcer healing time after infrainguinal bypass for critical leg ischemia. J Vasc Surg 2009;49:932-7.

35. Luther $\mathrm{M}$, Kantonen I, Lepäntalo $\mathrm{M}$, et al. Arterial intervention and reduction in amputation for chronic critical leg ischaemia. Br J Surg 2000;87:454-8.

36. Winell K, Niemi M, Lepäntalo M. The national hospital discharge register data on lower limb amputations. Eur J Vasc Endovasc Surg 2006;32:66-70 